\title{
Experiência da Inserção das "Humanidades Médicas" no Módulo Biológico Ii do Curso de Medicina
}

\author{
Moreira, Simone da Nóbrega Tomaz; Sá, Joceline Cássia Ferenzini de; Nascimento \\ Júnior, Expedito Silva; Camilo, Christina da Silva; Azevedo, George Dantas de \\ Universidade Federal do Rio Grande do Norte - simonetomaz@hotmail.com
}

INTRODUÇÃO: a educação médica vem passando por um processo de mudança, buscando adequar a estrutura curricular ao contexto da prática profissional e, em especial, as necessidades de saúde da população. Mudanças no paradigma da saúde são necessárias, valorizando não apenas os aspectos biológicos, mas também os psicossociais do processo saúde-doença. Diante disso, vem crescendo uma área de reflexão e pensamento denominada "Humanidades Médicas", que se propõe a incluir temas das ciências humanas no curso de graduação. OBJETIVOS: descrever, a partir de uma reflexão crítica, a experiência do ensino das humanidades médicas dentro do módulo morfofuncional ("Módulo Biológico II" - MB II) MÉTODOS: O MB II compreende conteúdos de anatomia, histologia, embriologia, fisiologia e biofísica, totalizando 360 horas, duração de 15 semanas e integra a grade curricular do segundo período do curso. Desde 2009.2, tem sido disponibilizadas 30 horas (2créditos) para os temas das Ciências Humanas. a cada semestre, um total de 50 alunos são matriculados neste módulo, sendo as atividades humanísticas desenvolvidas em pequenos grupos ( 3 grupos de 16 ou 17 estudantes, a depender do tamanho da turma). São utilizadas metodologias ativas de ensino-aprendizagem, com ênfase no caráter formativo e na valorização da percepção e vivência dos estudantes. Cada grupo tem cinco encontros, cujo conteúdo programático é planejado em articulação com os conteúdos biológicos, sendo realizadas entrevistas com médicos e/ou sociedade, exibição e discussão de filmes, dinâmicas de grupo e "roleplaying". Além disso, os alunos fazem visitas a uma comunidade de baixa renda, onde observam o contexto social das pessoas, como também conversam com a comunidade sobre o acesso aos serviços de saúde. em outro momento, visitam um cenário hospitalar, onde têm a oportunidade de conversar com pessoas doentes, para que saibam mais sobre essas pessoas, buscando valorizar, de igual modo, os aspectos biopsicossociais. 0 aporte teórico acontece por meio de leituras de texto e discussões críticas nos grupos. RESULTADOS: ao final dos semestres, os alunos têm avaliado essas atividades, considerando-as importantes para a formação integral e generalista do médico. dos estudantes avaliados, 99\% classificaram-nas positivas, sendo consideradas "boa" (33\%), "muito boa" (29\%) e "excelente"(37\%). com relação às aulas práticas (visitas à comunidade e ao hospital), $92 \%$ e $90 \%$ classificaram como "muito boa" e "excelente", respectivamente. a análise qualitativa apontou que essas atividades contribuíram para a ampliação da percepção dos estudantes, no que se refere ao processo saúde-doença, como também para o entendimento sobre o sistema público de saúde. Os estudantes apontaram para a necessidade de continuidade e fortalecimento dessas atividades ao longo do curso. CONCLUSÃO: a estratégia inovadora utilizada mostrou ser viável a integração dos temas da área de humanas com os conteúdos biológicos. Essas atividades estiveram fundamentadas nos princípios da aprendizagem significativa, que valoriza os aspectos cognitivos e afetivos da aprendizagem, levando em consideração três alicerces: teoria, prática e desenvolvimento pessoal. Entretanto, cabe ressaltar que, mesmo abrindo espaço para a introspecção, reflexão pessoal e contato com os próprios sentimentos, em hipótese nenhuma, o espaço pedagógico é transformado em psicoterapêutico.

Nóbrega, Simone da; Moreira, Tomaz; Sá, Joceline Cássia Ferenzini de, Camilo, Christina da Silva; Nascimento Júnio, Expedito Silva; Azevedo, George Dantas de. Experiência da Inserção das "Humanidades Médicas" no Módulo Biológico li do Curso de Medicina. In: Anais do Congresso Internacional de Humanidades \& Humanização em Saúde [= Blucher Medical Proceedings, num.2, vol.1]. São Paulo: Editora Blucher, 2014. ISSN 2357-7282

DOI 10.5151/medpro-cihhs-10190 